\title{
Effects of Gilsonite on Performance Properties of Bitumen
}

\author{
Perviz AHMEDZADE ${ }^{1}$ \\ Omar ALQUDAH ${ }^{2}$ \\ Taylan GUNAY ${ }^{3}$ \\ Tacettin GECKIL ${ }^{4}$
}

\begin{abstract}
The effectiveness of natural Gilsonite on the performance properties of modified bitumens was studied. Three samples having different ratios of Gilsonite that are $6 \%, 8 \%$ and $10 \%$ by weight of base bitumen which was PG 64-16 grade were prepared. The physical properties and storage stabilities of four samples were investigated by means of conventional tests. The short-term and long-term aging processes of bitumens were conducted with rolling thin oven and pressure aging vessel tests, respectively. Rheological properties of bitumens were examined by means of Superpave tests such as rotational viscosity, dynamic shear rheometer and bending beam rheometer. After the rheological study, the low and high temperature performance classes of bitumens were determined by the Superpave specification. The results showed that natural Gilsonite-modified bitumens provide improvement in rheological and physical properties of bitumen, and were found highly compatible with base bitumen. Gilsonite additive significantly increased stiffness and viscosity of bitumen, and improved the resistance against fatigue cracking and rutting of bitumen, without causing a reduction in thermal cracking resistance of bitumen.
\end{abstract}

Keywords: Bitumen, gilsonite, aging, rheological properties, performance grade.

\section{INTRODUCTION}

In the modern world, annually about 110 million metric tons of bitumen is needed. The manufacture, repair and maintenance of bituminous pavements require the large amount of

\section{Note:}

- This paper was received on August 21, 2020 and accepted for publication by the Editorial Board on September 28, 2020.

- Discussions on this paper will be accepted by May 31, 2020.

- https://doi.org/10.18400/tekderg.783300

1 Ege University, Department of Civil Engineering, Izmir, Turkey - perviz.ahmedzade@ege.edu.tr https://orcid.org/0000-0001-8348-5901

2 German Jordanian University, Civil \& Environmental Engineering Department, Madaba, Jordan omerkudah@yahoo.com - https://orcid.org/0000-0003-1789-6749

3 Ege University, Department of Civil Engineering, Izmir, Turkey - taylan.gunay@ege.edu.tr https://orcid.org/0000-0002-2669-6320

4 Inonu University, Department of Civil Engineering, Malatya, Turkey - tacettin.geckil@inonu.edu.tr https://orcid.org/0000-0001-8070-6836 
fund and energy [1]. In addition to the high cost and inadequate resources of the bitumen used in road pavements, the aging due to transportation, storage, mixing, placement on the road surface and service life on the road also causes many problems. Moreover, after the application of bitumen, hot mix asphalt (HMA) pavements are also faced with various problems during their service life [2]. As is known, the main distresses occur in flexible pavements due to traffic loading or environmental effects or other factors, such as fatigue cracking, rutting, and low-temperature cracking [3].

The bitumen plays an important role in the performance properties of HMA during service life. However, many of the distresses are related to the characteristics of bitumen used in the pavement itself. Base binder is commonly used in most countries where some defections could be occurred early stages of service life. The rheological weakness of binder is the main reason of using modifiers to enhance properties of binder, and consequently make the performance of the pavements better. By the processes of mechanical mixing or chemical reaction, polymer modified bitumens (PMBs) are produced by adding polymers into bitumens. It is necessary appropriate compatibility between bitumen and polymer to obtain the optimum properties of PMBs. Poor storage stability occurs when the compatibility is poor. Thus, the separation of polymeric and bituminous phases or inconsistent bitumen quality takes place [4].

Bitumen modifiers could be natural or artificial. Many types of modifiers were used in this field, like rubber, crumb rubber, elvaloy, polypropylene, styrene-butadiene-rubber (SBR), and styrene butadiene styrene (SBS), and ethylene vinyl acetate (EVA) [3,5,6]. It is known that modifiers vary in effectiveness, workability, performance, availability, and cost. The cost efficiency as well as the degree of compatibility of modifier with the bitumen during storing and handling have been the biggest challenges in the industry of modified bitumens. Despite the fact that there is large number of modifiers, few of them are really appropriate for modification process. There have been many attempts within this scope to solve the problem related to lack of stability in polymer-modified bitumen. For example, the recycled polymers can be exposed to irradiation to get over this problem. In this process, functional groups and new bonds are formed in polymer chain and this provides chemical bonding with bitumen by preventing phase separation. The beneficial and significant enhancement of bitumen behavior and performance was obtained by the modification of bitumen with the electron irradiated recycled low-density polyethylene $\left(\mathrm{e}-\mathrm{LDPE}_{\mathrm{R}}\right)[7,8]$. The compatibility between SBS-g-M grafted with vinyl monomer under x-rays irradiation and bitumen, and thus the storage stability of bitumen was improved considerably as compared with SBS modified bitumen [9].

The main purpose of bitumen modification is to improve the main quality and properties of bitumen without negatively affecting the different properties of the bitumen or mixture [10]. In recent years, natural hydrocarbon-containing additives have begun to be used to improve the performance properties of bitumen. One of these additives is known in the market as Gilsonite, which is derived from naturally occurring bitumen resources, commonly referred to as asphaltite $[11,12,13,14]$. Discovered in the early $1860 \mathrm{~s}$, Gilsonite is a resinous hydrocarbons that has been used and evaluated in a variety of industrial applications [15]. Gilsonite, a crude petroleum-based by-product, contains natural hydrocarbons with a purity of about $99 \%$, and $57-70 \%$ of asphaltene $[14,16]$. It is a mineral bitumen, black and fragile, and has a structure that can easily be crushed into powder $[14,17]$. It is also a fast-dissolving 
additive in bitumen due to its easy using and good compatibility with bitumen [18]. The favorable properties of Gilsonite make it a good alternative to other commercially produced polymers, especially at high temperatures and high traffic volumes. In various studies, Gilsonite is generally used to improve high temperature performance properties due to the hardening effect of bitumen, but the hardening that occurs can affect the low and intermediate temperature performance characteristics of bitumen [13-15,19,20,21]. The use of Gilsonite is now considered very seriously in bitumen modification when cost and time effectiveness, high performance and storage stability are taken into consideration.

In this study, the Gilsonite, a natural hydrocarbon-containing additive, was used as a modifier for bitumen to examine its impact on the physical and rheological performance properties of the road bitumens.

Generally, in the studies carried out, the Gilsonite additive was used in bitumen modification in two different ways: the addition of Gilsonite into bitumen, or the addition of Gilsonite as a filler in the aggregate mixture [14]. In previous studies, it has been reported that the use of Gilsonite in bitumen modification has increased the viscosity and softening point of bitumen but decreased its ductility and penetration $[13,14,22]$. In some studies, it has been reported that Gilsonite reduced the temperature sensitivity by increasing the hardness of the bitumen, but it increased its elasticity $[13,23]$. In many studies it has been indicated that increasing the amount of Gilsonite in the bitumen increased the high temperature performance of the bitumen, but the tendency to fatigue and low-temperature cracking increased [11,1215,21,24]. However, Feng and Ameri have reported that the intermediate and high temperature performance of the modified bitumen with Gilsonite has improved [23]. The results of another study showed that Gilsonite, as a modifier, could be used to improve its stiffness properties and rutting resistance of mixtures used in hot climates [14]. A study, in which two different types of bitumen were used, indicate that Gilsonite improved the high temperature performances of the bitumens, but decreased the low temperature performances [17]. Similarly, Anderson et al. also noted that Gilsonite modified bitumen showed a fragile behavior at low temperatures [19]. The results of a study showed that the Gilsonite-modified bitumens serve to prevent crack formation in the coating by forming a good bond between bitumen and aggregate [25]. In another study, it was found that the storage stability of Gilsonite-modified bitumen was better than SBS modified bitumen [13]. In addition, the results of a study showed that the use of Gilsonite in appropriate amount had no negative effect on the aging process of bitumen [26]. In many studies it has been reported that HMA modified with Gilsonite had higher stability, lower permanent deformation and better fatigue and moisture resistance $[10,13,15,18,23]$. Additionally, it has been determined that these mixtures showed more strength under dynamic loading [15,23]. Moreover, in some studies it has been stated that Gilsonite has many economic benefits of using it in pavement design $[11,13,14,15,23]$. Finally, it has been suggested that Gilsonite could be used as a modifier to improve the performance properties of HMA $[11,13]$.

This research discusses the influence of Gilsonite as a modifier in bitumen. The primary objective of this research is to characterize the physical and rheological properties of Gilsonite modified bitumen. To this end, the test results of modified binders were discussed and compared with base (unmodified) bitumen. 


\section{MATERIALS}

\subsection{Materials}

The base bitumen with a PG 64-16 performance grade used in this study was supplied from Izmit refinery in Turkey. The obtained physical properties of base bitumen were given in Table 1. The modifier used was natural Gilsonite material supplied by URAN Holding Ltd. Company in Turkey. The composition and physical properties of used Gilsonite are shown in Table 2.

Table 1 - Physical properties of base bitumen (PG 64-16)

\begin{tabular}{|c|c|}
\hline Properties & Results \\
\hline Penetration $\left(25^{\circ} \mathrm{C}, 100 \mathrm{gr}, 5 \mathrm{sec}\right) 0.1 \mathrm{~mm}$ & 51 \\
\hline Softening point, ${ }^{\circ} \mathrm{C}$ & 46.5 \\
\hline Elastic recovery $\left(25^{\circ} \mathrm{C}\right), \%$ & 88 \\
\hline Flash point, ${ }^{\circ} \mathrm{C}$ & 265 \\
\hline Specific gravity $\left(25^{\circ} \mathrm{C}\right), \mathrm{gr} / \mathrm{cm}^{3}$ & 1.027 \\
\hline
\end{tabular}

Table 2 - Composition and physical properties of used Gilsonite

\begin{tabular}{|c|c|}
\hline Properties & Results \\
\hline Carbon content (\%) & 85.22 \\
\hline Sulphur content (\%) & 3.09 \\
\hline Oxygen content (\%) & 1.49 \\
\hline Hydrogen content (\%) & 5.97 \\
\hline Nitrogen content (\%) & 0.77 \\
\hline Ash content $(\%)$ & 2.24 \\
\hline Moisture content (\%) & 0.09 \\
\hline Solubility in CS2 (\%) & 41.74 \\
\hline Solubility in Toluene (\%) & 20.83 \\
\hline Softening point, ${ }^{\circ} \mathrm{C}$ & $160-205$ \\
\hline Specific gravity, at $25^{\circ} \mathrm{C}\left(\mathrm{gr} / \mathrm{cm}^{3}\right)$ & 1.145 \\
\hline
\end{tabular}

\subsection{Preparation of Samples}

The Gilsonite-modified bitumen were prepared by blending base bitumen with Gilsonite in powder form at three different percentages $(6 \%, 8 \%$ and $10 \%)$ of Gilsonite by total weight of bitumen. For this purpose, blending process was accomplished via a laboratory high shear mixer. After heated in oven for $90 \mathrm{~min}$ at $163^{\circ} \mathrm{C}$, the base bitumen was poured into a 
temperature-controlled container of mixer rotating $500 \mathrm{rpm}$. Subsequently the Gilsonite was slowly added into bitumen by portions within the first 15 minutes of mixing, and then the mixing rate was adjusted to $1500 \mathrm{rpm}$. This mixing process continued for another $45 \mathrm{~min}$. The mixing temperature was set at $170{ }^{\circ} \mathrm{C}$ and the temperature was checked with a thermometer at every 15 minutes.

Base and Gilsonite-modified bitumens used in this study were coded as $\mathrm{B}, \mathrm{B}+6 \mathrm{G}, \mathrm{B}+8 \mathrm{G}$ and $\mathrm{B}+10 \mathrm{G}$, respectively.

\section{TEST METHODS}

\subsection{Conventional Tests}

Penetration, softening and flash point, elastic recovery, and specific gravity tests were performed on both original base and modified bitumens. After the thin film oven test (RTFOT), the mass losses, retained penetrations and softening points of the bitumen were established to understand the effects of the modifier on aging. All tests were conducted according to the requirements of (TS EN 14023) standard of polymer-modified bitumens (PMBs) [27].

\subsection{Storage Stability Test}

In order to provide the stability and decomposition resistance of the modified bitumens during handling, mixing and in-service life, the compatibility test was also performed throughout the storage stability test according to EN 13399 standard [28].

This test was conducted as follows. A glass tube consists of three symmetrical parts, $35 \mathrm{~mm}$ diameter, and $180 \mathrm{~mm}$ height, was used and filled with about $150 \mathrm{~g}$ of modified bitumen. The tubes containing the modified samples were tightly closed via glass hood with two hooks. Two small springs were used to close the tube and fasten the hood with the top part of the tube in order to ensure no vaporization problem would occur during the test. After that, the tubes were placed vertically in a preheated oven in $180{ }^{\circ} \mathrm{C}$ for $72 \mathrm{hr}$. The bitumen samples stored in oven were cooled at room temperature, and then cut into three parts. To compare the top and bottom parts of samples, these two parts were tested to evaluate the storage stability by measuring their penetration, softening point [29].

\subsection{Rotational Viscosity Test}

The viscosities of all bitumens were determined by the rotational viscometer (RV) to ensure the workability of the modified bitumens. The rotational viscometer as compared with the capillary viscometers used in the viscosity graded method can detect the viscosity of bitumen by measuring the torque required to provide a constant rotational speed (20 RPM) of a cylindrical spindle immersed into a binder sample held at a fixed temperature [29, 30].

The tests were conducted at $135^{\circ} \mathrm{C}$ and $165^{\circ} \mathrm{C}$ by means of a Brookfield viscometer (DVRVII Pro) as described in AASHTO T316 standard [31]. The mixing and compacting process temperatures of base and modified bitumens to be used in HMA were also determined. In the 
calculation, the suitable ranges of viscosities corresponding to the mixing and compacting temperatures were selected as $150-190 \mathrm{cP}$ and $250-310 \mathrm{cP}$, respectively. The rotational viscosity of bitumen should not exceed $3000 \mathrm{cP}$ for the tests at $135^{\circ} \mathrm{C}$ [32].

\subsection{Aging of Bitumen}

The short-term aging operations of all bitumens were conducted with the rolling thin film oven test (RTFOT) according to EN 12607-1 standard [33]. The bitumen samples were aged for $75 \mathrm{~min}$ in an oven at a temperature of $163{ }^{\circ} \mathrm{C}$. After RTFOT simulating changes in the physical properties of the bitumen during mixing and construction, the bitumens were subjected to penetration and softening point tests. In addition, the mass losses of the bitumens were also determined to understand the effects of the short-term aging. The Superpave specification for RTFOT aged bitumen implies that maximum mass loss after short-term aging process should not exceed 1\% by weight of bitumen; for which TS EN 14023 standard is different depending on PG grade of tested bitumen [34]. For soft bitumens the maximum limit is $1 \%$, and for harder bitumens it is $0.8 \%$ by weight of bitumen [27]. As is known, bitumen are exposed to heat and pressure to simulate the long-term aged bitumen in field during service; the pressure aging vessel (PAV) was used to simulate in-service aging over a 7 to 10 -year period $[32,35]$.

\subsection{Rheological Characterization}

The viscous and elastic behavior of bitumen was determined by the dynamic shear rheometer (DSR) at medium to high temperatures. The complex shear modulus $\left(G^{*}\right)$ and phase angle $(\delta)$ were measured by subjecting a small sample of bitumen to oscillatory shear stresses as sandwiched between two parallel plates in the DSR machine in stress controlled mode at a frequency of $10 \mathrm{rad} / \mathrm{s}$. Non-aged and RTFOT samples were tested using $25 \mathrm{~mm}$ diameter plates and a gap of $1 \mathrm{~mm}$. After RTFOT + PAV aging, samples are tested using $8 \mathrm{~mm}$ diameter plates and a $2 \mathrm{~mm}$ thickness sample. The rutting parameters $\left(G^{*} / \sin \delta\right)$ at high temperatures of the bitumen and the fatigue parameters $\left(G^{*} \sin \delta\right)$ at the intermediate temperatures are calculated for each sample. The $G^{*} / \sin \delta$ of original bitumen should not exceed $1 \mathrm{kPa}$, and for RTFOT aged bitumen it should not exceed $2.2 \mathrm{kPa}$. Furthermore, the $G^{*} \sin \delta$ of RTFOT+PAV aged bitumen should not exceed $5000 \mathrm{kPa}[32,36]$.

\subsection{Bending Beam Rheometer (BBR) Test}

The bending beam rheometer (BBR) test is used to determine the stiffness and consistency properties of bitumen at low temperatures. The obtained parameters are considered to be indicative of the ability of the bituminous binder to resist the low temperature cracking. The BBR test is also used to determine the performance grades (PG) of the bitumens at low temperatures. Properties of bitumen at low temperatures, the creep stiffness (s) and the creep rate ( $m$-value), are measured using BBR. Superpave specification entails that the creep stiffness must not exceed $300 \mathrm{MPa}$, and creep rate should not be lower than 0.300 to avoid low temperature cracking $[17,22]$. 


\section{RESULTS AND DISCUSSIONS}

The criterion applied in this research to evaluate Gilsonite effects on base bitumen was at first to determine the PG grade of the bitumens, and then to compare obtained conventional tests results and rheological properties with requirements of TS EN 14023 standard of polymer-modified bitumens (PMBs) at the specified PG grade of each bitumen. To evaluate the properties of the modified bitumen according to TS EN 14023 standard, the PG grade of this bitumen must be known in advance. For this reason, the conventional test results of modified bitumens including both before and after the short-term aging were intentionally given in Table 3.

Table 3 - Evaluation of modified bitumen according to TS EN 14023 standard for (PMBs)

\begin{tabular}{|c|c|c|c|c|}
\hline Tests / Binder types & $\begin{array}{c}\text { B } \\
\text { (PG 64-16) }\end{array}$ & $\begin{array}{c}\mathrm{B}+6 \mathrm{G} \\
(\mathrm{PG} 70-16)\end{array}$ & $\begin{array}{c}\mathrm{B}+8 \mathrm{G} \\
(\mathrm{PG} 76-16)\end{array}$ & $\begin{array}{c}\mathrm{B}+10 \mathrm{G} \\
(\mathrm{PG} 82-16)\end{array}$ \\
\hline $\begin{array}{l}\text { Penetration }\left(25^{\circ} \mathrm{C}, 100 \mathrm{gr}, 5 \mathrm{sec}\right) \text {, } \\
0.1 \mathrm{~mm}\end{array}$ & $\begin{array}{c}51 \\
(50-70)\end{array}$ & $\begin{array}{c}30 * \\
(45-80)\end{array}$ & $\begin{array}{c}28 \\
(25-55)\end{array}$ & $\begin{array}{c}22 * \\
(25-55)\end{array}$ \\
\hline Softening point, ${ }^{\circ} \mathrm{C}$ & $\begin{array}{c}46.5 \\
(46-54)\end{array}$ & $\begin{array}{l}52^{*} \\
(\geq 60)\end{array}$ & $\begin{array}{l}53^{*} \\
(\geq 65)\end{array}$ & $\begin{array}{l}53^{*} \\
(\geq 70)\end{array}$ \\
\hline Elastic recovery $\left(25^{\circ} \mathrm{C}\right), \%$ & - & $\begin{array}{c}87 \\
(\geq 60)\end{array}$ & $\begin{array}{c}86 \\
(\geq 60)\end{array}$ & $\begin{array}{l}84.5 \\
(\geq 60)\end{array}$ \\
\hline Flash point, ${ }^{\circ} \mathrm{C}$ & $\begin{array}{c}250 \\
(\geq 230)\end{array}$ & $\begin{array}{c}255 \\
(\geq 220) \\
\end{array}$ & $\begin{array}{c}255 \\
(\geq 220)\end{array}$ & $\begin{array}{c}260 \\
(\geq 220)\end{array}$ \\
\hline Specific gravity $\left(25^{\circ} \mathrm{C}\right), \mathrm{gr} / \mathrm{cm}^{3}$ & $\begin{array}{c}1.027 \\
(1.0-1.1)\end{array}$ & $\begin{array}{c}1.036 \\
(1.0-1.1)\end{array}$ & $\begin{array}{c}1.039 \\
(1.0-1.1)\end{array}$ & $\begin{array}{c}1.042 \\
(1.0-1.1)\end{array}$ \\
\hline \multicolumn{5}{|l|}{ Storage stability: } \\
\hline Difference in softening point, ${ }^{\circ} \mathrm{C}$ & - & $\begin{array}{l}1.5 \\
(\leq 5)\end{array}$ & $\begin{array}{c}0.5 \\
(\leq 5)\end{array}$ & $\begin{array}{l}1.5 \\
(\leq 5)\end{array}$ \\
\hline Difference in penetration, $0.1 \mathrm{~mm}$ & - & $\begin{array}{c}2 \\
(\leq 13)\end{array}$ & $\begin{array}{c}1 \\
(\leq 9)\end{array}$ & $\begin{array}{c}1 \\
(\leq 9)\end{array}$ \\
\hline $\begin{array}{l}\text { Dynamic shear rheometer (DSR) } \\
\left(G^{*} / \sin \delta>1 \mathrm{kPa}\right) \\
\text { Failure temperature, }\left({ }^{\circ} \mathrm{C}\right)\end{array}$ & $\begin{array}{c}68 \\
(\geq 64)\end{array}$ & $\begin{array}{c}74.7 \\
(\geq 70)\end{array}$ & $\begin{array}{c}77 \\
(\geq 76)\end{array}$ & $\begin{array}{c}82 \\
(\geq 82)\end{array}$ \\
\hline \multicolumn{5}{|l|}{ Rolling thin oven test (RTFOT): } \\
\hline Weight loss, \% & $\begin{array}{l}0.295 \\
(\leq 0.5)\end{array}$ & $\begin{array}{c}0.036 \\
(\leq 1)\end{array}$ & $\begin{array}{l}0.031 \\
(\leq 0.8)\end{array}$ & $\begin{array}{l}0.029 \\
(\leq 0.8)\end{array}$ \\
\hline \multicolumn{5}{|l|}{ Change in softening point: } \\
\hline Increase, ${ }^{\circ} \mathrm{C}$ & $\begin{array}{c}5.5 \\
(\leq 9) \\
\end{array}$ & $\begin{array}{c}7.5 \\
(\leq 8) \\
\end{array}$ & $\begin{array}{c}7.5 \\
(\leq 8) \\
\end{array}$ & $\begin{array}{c}7 \\
(\leq 8) \\
\end{array}$ \\
\hline Decrease, ${ }^{\circ} \mathrm{C}$ & - & $\begin{array}{l}- \\
(\leq 5)\end{array}$ & $\begin{array}{c}- \\
(\leq 5)\end{array}$ & $\begin{array}{l}- \\
(\leq 2)\end{array}$ \\
\hline Retained penetration, $\%$ & $\begin{array}{c}53 \\
(\geq 50)\end{array}$ & $\begin{array}{c}80 \\
(\geq 50)\end{array}$ & $\begin{array}{l}78.6 \\
(\geq 45)\end{array}$ & $\begin{array}{l}77.4 \\
(\geq 40)\end{array}$ \\
\hline
\end{tabular}


Table 3 - Evaluation of modified bitumen according to TS EN 14023 standard for (PMBs) (continue)

\begin{tabular}{|c|c|c|c|c|}
\hline Tests / Binder types & $\begin{array}{c}\text { B } \\
\text { (PG 64-16) }\end{array}$ & $\begin{array}{c}\mathrm{B}+6 \mathrm{G} \\
(\mathrm{PG} 70-16)\end{array}$ & $\begin{array}{c}\mathrm{B}+8 \mathrm{G} \\
(\mathrm{PG} 76-16)\end{array}$ & $\begin{array}{c}\mathrm{B}+10 \mathrm{G} \\
(\mathrm{PG} 82-16)\end{array}$ \\
\hline $\begin{array}{l}\text { Dynamic shear rheometer }(\mathrm{DSR}) \\
\text { RTFOT aged }\left(G^{*} / \sin \delta>2.2 \mathrm{kPa}\right) \\
\text { Failure temperature, }\left({ }^{\circ} \mathrm{C}\right)\end{array}$ & $\begin{array}{c}68.5 \\
(\geq 64)\end{array}$ & $\begin{array}{c}75.5 \\
(\geq 70)\end{array}$ & $\begin{array}{c}78.7 \\
(\geq 76)\end{array}$ & $\begin{array}{c}>82 \\
(\geq 82)\end{array}$ \\
\hline $\begin{array}{l}\text { Dynamic shear rheometer }(\mathrm{DSR}) \\
\text { RTFOT+PAV aged } \\
\left(G^{*} \sin \delta<5000 \mathrm{kPa}\right) \\
\text { Failure temperature, }\left({ }^{\circ} \mathrm{C}\right)\end{array}$ & $\begin{array}{c}25 \\
(\leq 31)\end{array}$ & $\begin{array}{l}23.4 \\
(\leq 31)\end{array}$ & $\begin{array}{l}25.2 \\
(\leq 34)\end{array}$ & $\begin{array}{l}27.1 \\
(\leq 37)\end{array}$ \\
\hline $\begin{array}{l}\text { Bending beam rheometer (BBR) } \\
\text { Stiffness ( } \leq \leq 300 \mathrm{MPa}, m \geq 0.300) \\
\text { Failure temperature, }\left({ }^{\circ} \mathrm{C}\right)\end{array}$ & $\begin{array}{l}-20.5 \\
(\leq-16)\end{array}$ & $\begin{array}{l}-19.9 \\
(\leq-16)\end{array}$ & $\begin{array}{l}-19.3 \\
(\leq-16)\end{array}$ & $\begin{array}{l}-18.3 \\
(\leq-16)\end{array}$ \\
\hline
\end{tabular}

() Requirements of binders according to standard.

${ }^{*}$ Result does not achieve the required specification.

\subsection{Conventional Bitumen Tests Results}

The results of penetration and softening point tests conducted on bitumens were given in Table 3. As seen in Table 3, the penetration was continuously in the decreasing trend with increasing Gilsonite additive, and therefore, $\mathrm{B}+10 \mathrm{G}$ had the lowest penetration with a value of $22 \mathrm{dmm}$. The softening point of the bitumen increased with increasing Gilsonite addition, confirming the results of the penetration test. These results mean a significant increase in the stiffness of the bitumen after Gilsonite addition. However, this is accompanied by a decrease in elastic recovery since bitumen becomes harder after the modification. However, Gilsonite had only a slight adverse effect on elastic properties of bitumen as the elastic recovery percentage decline to 84.5 (for $\mathrm{B}+10 \mathrm{G}$ ) from 88 (for $\mathrm{B}$ ). As for flash point tests, values for all the base and Gilsonite modified bitumen samples were found above the recommended minimum value of $220^{\circ} \mathrm{C}$.

As seen from Table 3, the tests performed on aged bitumens showed that the Gilsonite additive had a relatively positive effect on the aging potential of bitumens. The mass losses of modified bitumens were still very slight and its value was in the specified standard limits. The difference between softening point before and after aging within the specification for all bitumens. Additionally, after short-term aging, the retained penetrations of $\mathrm{B}, \mathrm{B}+8 \mathrm{G}$, and $\mathrm{B}+10 \mathrm{G}$ after RTFOT aging were $(80,78.6$, and 77.4$) \%$ of the original bitumens, respectively. This showed that as the decrease in retained penetration was very slight while Gilsonite content is increased from 6 to $10 \%$. This also indicated that the increase in the modifier content had a positive effect on short term aging.

\subsection{Storage Stability Test Results}

A long period of storage for bitumen could lead to phase separation of the bitumen and poor stability problems. This situation is a major problem in the modified bitumen industry. The 
results associated with storage stability was given in Table 4. Accordingly, both the softening point and the penetration results of the bottom and top parts of the Gilsonite-modified bitumen subject to the storage stability test are very close to each other. This result can be regarded as a good indicator of the homogeneity and consistency of Gilsonite modified bitumens.

Table 4 - Storage stability test results of Gilsonite modified bitumens

\begin{tabular}{|c|c|c|c|}
\hline Property / Bitumen types & B $+6 \mathrm{G}$ & $\mathrm{B}+8 \mathrm{G}$ & $\mathrm{B}+10 \mathrm{G}$ \\
\hline Penetration bottom part, 0.1 mm & 24 & 22 & 17 \\
\hline $\begin{array}{c}\text { Penetration top part, 0.1mm } \\
\text { Difference in penetration between bottom and } \\
\text { top part, 0.1 mm }\end{array}$ & 26 & 23 & 18 \\
\hline $\begin{array}{c}\text { Softening point bottom part, }{ }^{\circ} \mathrm{C} \\
\text { Softening point top part, }{ }^{\circ} \mathrm{C}\end{array}$ & 50.5 & 54 & 56.5 \\
\hline $\begin{array}{c}\text { Difference in softening point between bottom } \\
\text { and top part, }{ }^{\circ} \mathrm{C}\end{array}$ & 52 & 53.5 & 0.5 \\
\hline \begin{tabular}{c} 
P \\
\hline
\end{tabular} & 55 & 1.5 \\
\hline
\end{tabular}

\subsection{Rotational Viscosity Test Results}

The rotational viscosity (RV) of the bitumen was determined at 135 and $165{ }^{\circ} \mathrm{C}$, and the results were summarized in Table 5. The mixing and compacting temperatures and the modification indexes ( $\left.\eta_{\text {modified }} / \eta_{\text {base }}\right)$ of all bitumens to be used in HMA were also given in Table 5. Addition of Gilsonite to base bitumen increased the viscosity at $135^{\circ} \mathrm{C}$ and $165^{\circ} \mathrm{C}$. This indicates that Gilsonite modification improved the stiffness of bitumen. For instance, at the heavy modification level of $10 \%$, the viscosity increased from $443 \mathrm{cP}$ to $1122.5 \mathrm{cP}$. On the other hand, both mixing and compacting temperatures increased as the content of Gilsonite was increased.

Table 5 - Rotational viscosity test results of the base and Gilsonite modified bitumens

\begin{tabular}{|c|c|c|c|c|c|c|}
\hline \multirow{2}{*}{$\begin{array}{c}\text { Binder } \\
\text { types }\end{array}$} & \multicolumn{2}{|c|}{ Rotational viscosity $(\mathrm{cP})$} & \multicolumn{2}{c|}{$\eta_{\text {modified }} / \eta_{\text {base }}$} & \multicolumn{2}{c|}{ Temperature range $\left({ }^{\circ} \mathrm{C}\right)$} \\
\cline { 2 - 7 } & $135^{\circ} \mathrm{C}$ & $165^{\circ} \mathrm{C}$ & $135^{\circ} \mathrm{C}$ & $165^{\circ} \mathrm{C}$ & Mixing & Compaction \\
\hline $\mathrm{B}$ & 443 & 128 & 1.0 & 1.0 & $157-163$ & $145-150$ \\
\hline $\mathrm{B}+6 \mathrm{G}$ & 715 & 170 & 1.61 & 1.33 & $162-167$ & $152-157$ \\
\hline $\mathrm{B}+8 \mathrm{G}$ & 873 & 208 & 1.97 & 1.63 & $166-171$ & $156-161$ \\
\hline $\mathrm{B}+10 \mathrm{G}$ & 1122.5 & 255 & 2.53 & 1.99 & $172-177$ & $162-167$ \\
\hline
\end{tabular}

The mixing and compacting temperatures of the bitumen were detected by means of Figure 1. The mixing and compacting temperature ranges increased from (157-163) ${ }^{\circ} \mathrm{C}$ and (145-150) ${ }^{\circ} \mathrm{C}$ for B, to $(172-177){ }^{\circ} \mathrm{C}$ and $(162-167){ }^{\circ} \mathrm{C}$ for $\mathrm{B}+10 \mathrm{G}$, respectively. Although 
the workability of modified bitumen decreased, the value of RV was less than $3000 \mathrm{cP}$ and therefore still satisfied the ASTM D6373 standard criterion for bitumen workability [32, 38].

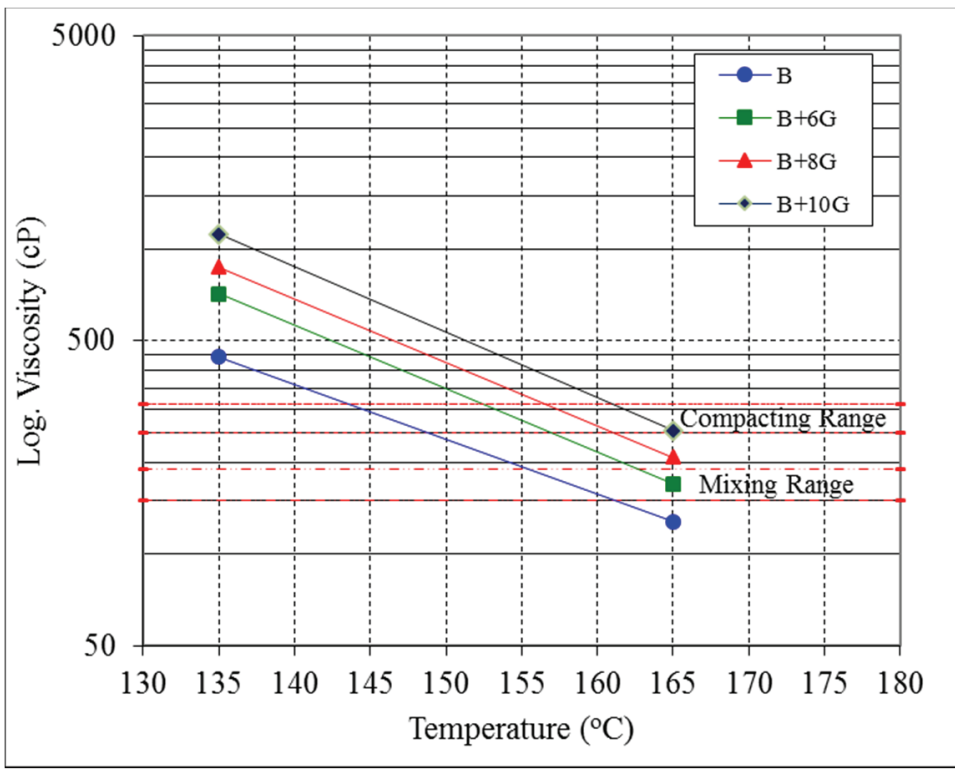

Figure 1 - Viscosity-temperature relationship for the base and Gilsonite modified bitumens

\subsection{Rheological Characterization- Dynamic Shear Rheometer (DSR) Test Results}

To determine the PG grade of each bitumen type and to study the effect of Gilsonite modification on rheological properties of bitumen, the DSR test was conducted. Viscoelastic parameters of all bitumens, such as complex modulus $\left(G^{*}\right)$ and phase angle $(\delta)$ were obtained, and the effect of Gilsonite on $G^{*}$ and $\delta$ for original and RTFOT-aged bitumens was shown in Figures 2 and 3, respectively. The rutting parameter $\left(G^{*} / \sin \delta\right)$ was calculated for each sample of base and modified bitumens and shown graphically in Figure 4.

As seen from Figure 2, the $G^{*}$ parameter for original base bitumen (B) for example at $64{ }^{\circ} \mathrm{C}$ was $1.64 \mathrm{kPa}$ and increased to $8.56 \mathrm{kPa}$ for $\mathrm{B}+10 \mathrm{G}$ at the same temperature. Adding $10 \%$ of Gilsonite leads to an increase of bitumen's stiffness by $421 \%$. It can be said that Gilsonite modification improved the stiffness of bitumen and rheological behavior especially under high temperatures.

As shown in Figure 3, the values of $\delta$ were decreased as Gilsonite content increased in original and aged bitumens. For example, $\delta$ at $64^{\circ} \mathrm{C}$ for $\mathrm{B}$ was 87.2 and for $\mathrm{B}+10 \mathrm{G}$ was 78.7 of original case. This indicated that Gilsonite exhibited an improvement of elastic component of bitumen.

The bitumen used in the mixture provides its fair share of the overall resistance in the pavement in terms of permanent deformations by controlling stiffness of the mixture at high temperatures. The rutting parameters $\left(G^{*} / \sin \delta\right)$ of base and modified bitumens were found for original and RTFOT aged bitumen at high levels of temperature starting at $52{ }^{\circ} \mathrm{C}$. While 
$G^{*} / \sin \delta$ value increased, the bitumen was expected to be stiffer and as a result more rut resistant mixtures could be achieved.

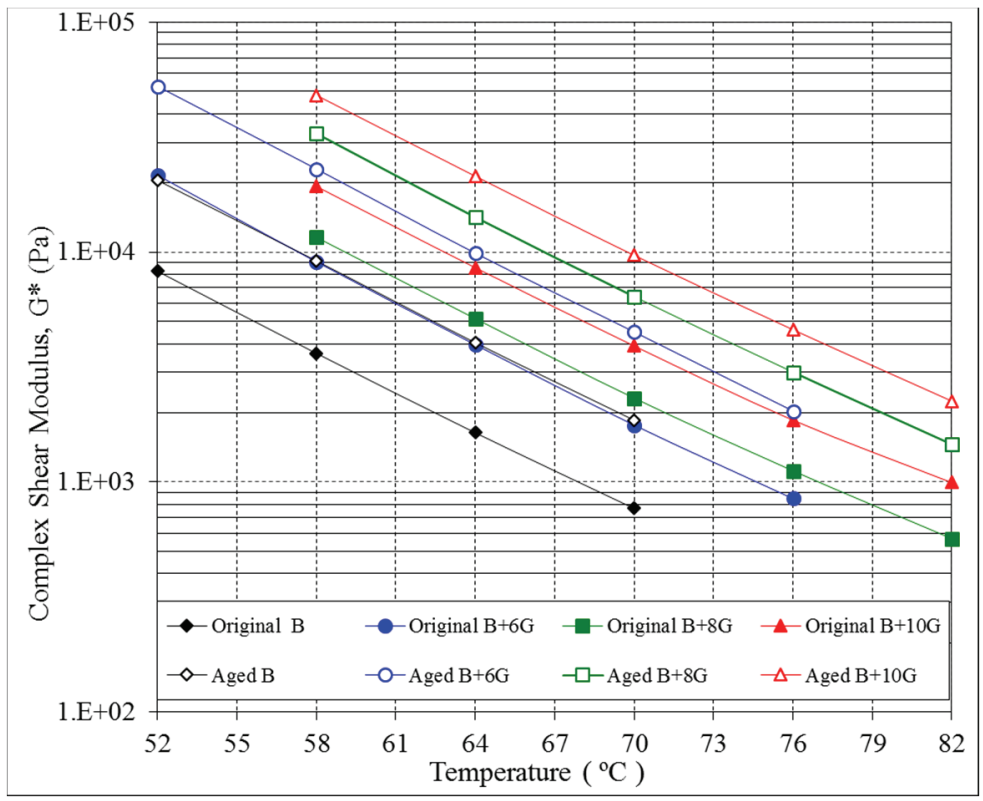

Figure 2 - Effect of Gilsonite on complex shear modulus $\left(G^{*}\right)$ for original and RTFOT aged bitumens

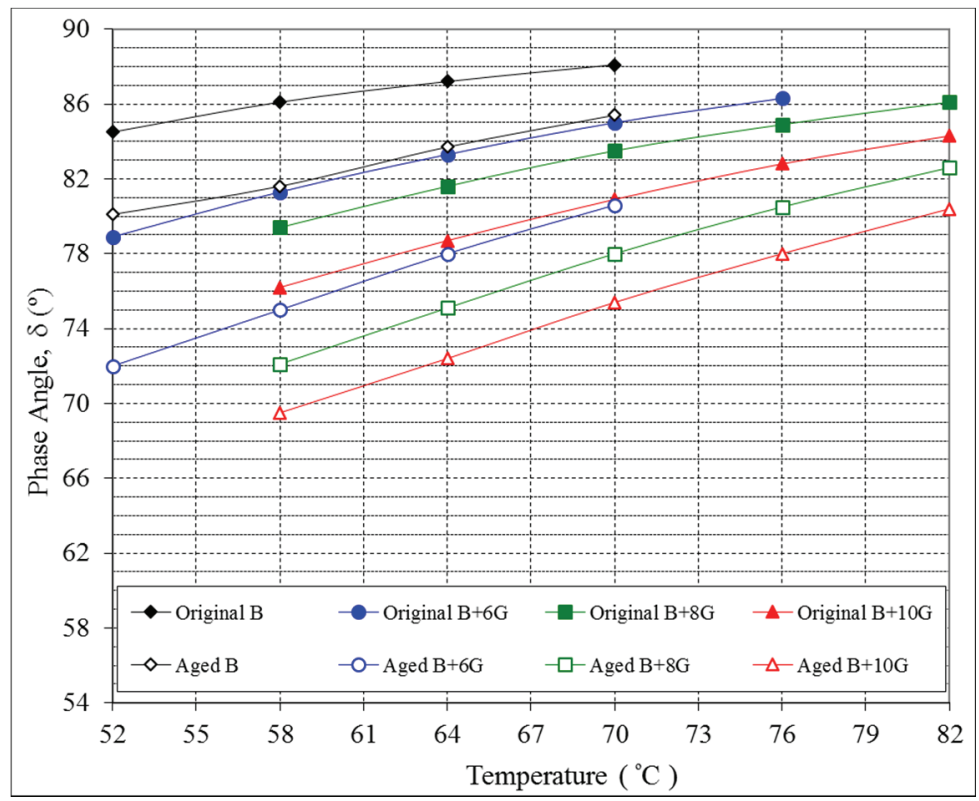

Figure 3 - Effect of Gilsonite on phase angle ( $\delta$ ) for original and RTFOT aged bitumens 


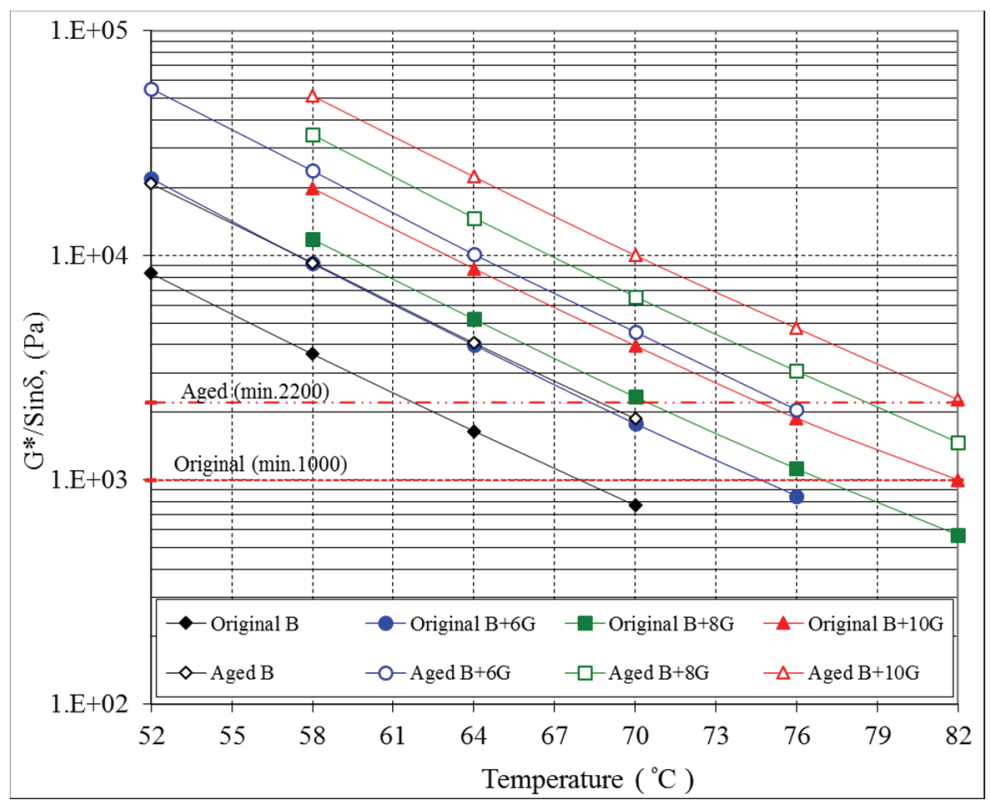

Figure 4 - Rutting performance of Gilsonite modified bitumens

Figure 4 showed the $G * / \sin \delta$ of original and RTFOT aged samples. B+10G has the highest $\mathrm{G}^{*} / \sin \delta$ value of $8.73 \mathrm{kPa}$ compared to the rest of samples. This showed that the stiffness of bitumen increased as Gilsonite content increased. This result was compatible with conventional test data.

$G^{*} / \sin \delta$ of aged sample was higher than that of the original sample of the same bitumen type. For example, at $64{ }^{\circ} \mathrm{C}$ the $G^{*} / \sin \delta$ for original B was $1.65 \mathrm{kPa}$ and for aged B was $4.07 \mathrm{kPa}$. At the same temperature, for original $\mathrm{B}+10 \mathrm{G}$ the $G^{*} / \sin \delta$ was also $8.73 \mathrm{kPa}$ and for aged $\mathrm{B}+10 \mathrm{G}$ was $22.4 \mathrm{kPa}$.

$G^{*} / \sin \delta$ of the base and modified bitumens (seen in Figure 4) indicate that aged $\mathrm{B}+8 \mathrm{G}$ provides the maximum increase in stiffness between the samples which is around $182.7 \%$ compared to base bitumen, whereas the aged $\mathrm{B}, \mathrm{B}+6 \mathrm{G}$, and $\mathrm{B}+10 \mathrm{G}$ exhibited the increases of $146.7,153.1$, and $156.6 \%$ respectively. As expected, the increment in temperature leads to a decrease in $G^{*}$ and an increase in $\delta$. Moreover, the B+10G shows much more resistance against permanent deformation rather than B. As can be seen in Figure 4, B+10G achieved the specifications of rutting parameter in terms of both aged and unaged conditions up to $82^{\circ} \mathrm{C}$, while $\mathrm{B}$ reaches only up to $64^{\circ} \mathrm{C}$ considering Superpave specifications.

To study the fatigue performance of Gilsonite-modified bitumen, complex shear modulus $\left(G^{*}\right)$ and phase angle $(\delta)$ for PAV-aged bitumen at different temperatures and different Gilsonite contents were shown in Figure 5 and 6 , respectively. The fatigue parameters $\left(G^{*} \sin \delta\right)$ for all bitumen types were calculated, and fatigue performance of Gilsonite modification was shown in Figure 7. The effects of the Gilsonite additive on the rheological properties of bitumen are summarized in Table 3 . 
Perviz AHMEDZADE, Omar ALQUDAH, Taylan GUNAY, Tacettin GECKIL

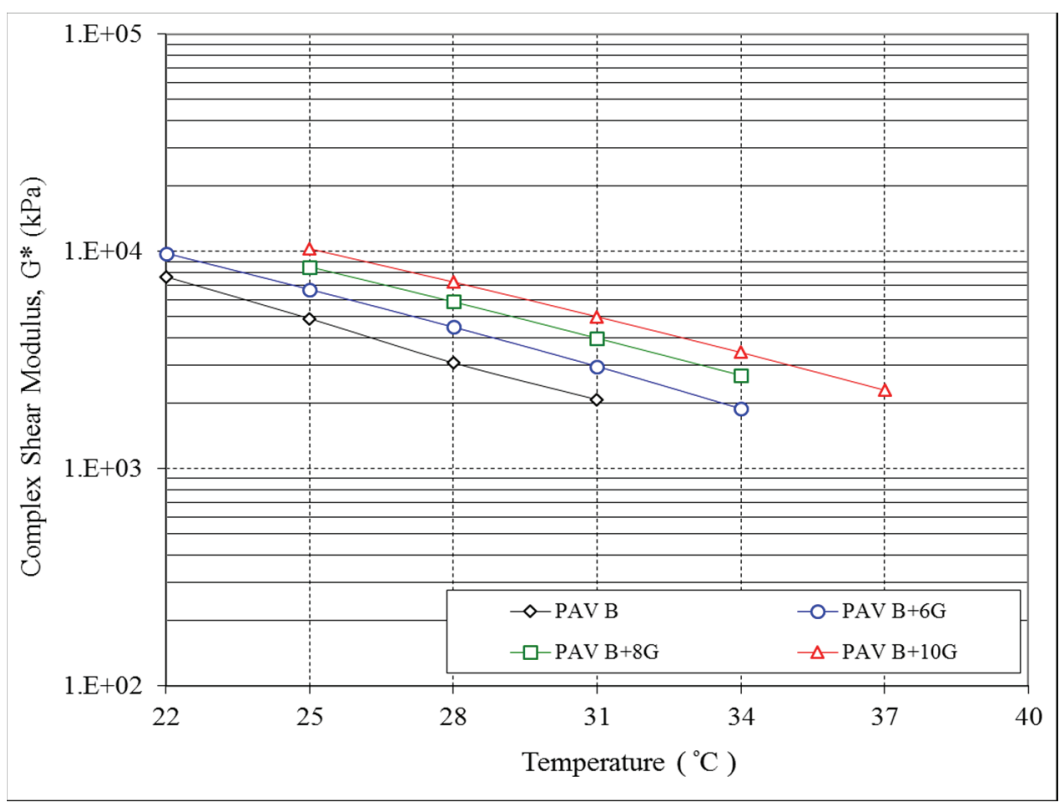

Figure 5 - Effect of Gilsonite on complex shear modulus ( $\left.G^{*}\right)$ for PAV aged bitumens

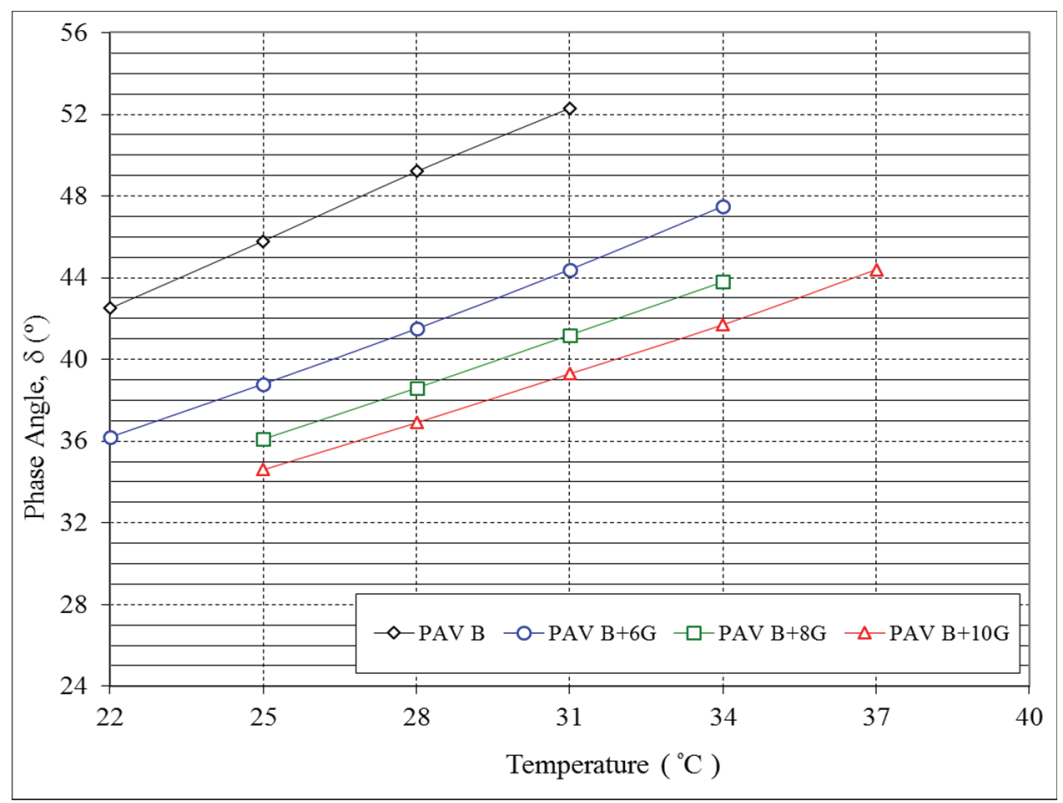

Figure 6 - Effect of Gilsonite on phase angle ( $\delta$ ) for PAV aged bitumens 


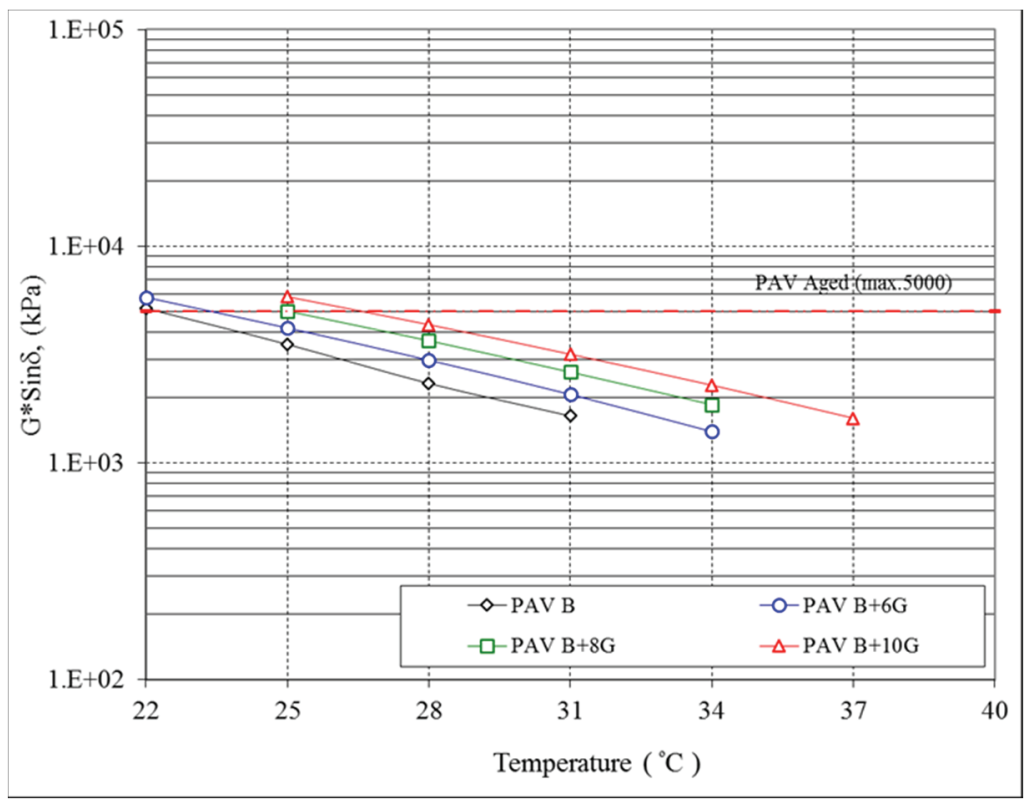

Figure 7 - Fatigue performance of Gilsonite modified bitumens

The fatigue parameters $\left(G^{*} \sin \delta\right)$ of modified bitumens increased with increasing Gilsonite content compared to the base bitumen due to the increase of $G^{*}$ and decrease in $\delta$. It should be noted that fatigue parameter was determined at intermediate test temperature by adding the high-grade temperature to the low-grade temperature dividing the result by 2 and adding 4. Hence, the comparison between the base bitumen $\mathrm{B}$ and $\mathrm{B}+10 \mathrm{G}$ should be related to the PG grade of each bitumen since stiffness differs from one bitumen to another. The PG grade of B was PG 64-16, therefore, the intermediate test temperature of RTFOT+PAV aged bitumen used in DSR test was calculated as $28^{\circ} \mathrm{C}$ (by using abovementioned formula which is correspond to $(64-16) / 2+4=28$ in this case). Similarly, from Table 5 for $\mathrm{B}+10 \mathrm{G}$ which is PG 82-16 graded bitumen, the intermediate test temperature was found as $37^{\circ} \mathrm{C}$ by using the same formula.

As can be seen in Figure 7, $G^{*} \sin \delta$ of B was found as $2327 \mathrm{kPa}$ at $28{ }^{\circ} \mathrm{C}, 2070 \mathrm{kPa}$ at $31{ }^{\circ} \mathrm{C}$ for $\mathrm{B}+6 \mathrm{G}, 1858 \mathrm{kPa}$ at $34^{\circ} \mathrm{C}$ for $\mathrm{B}+8 \mathrm{G}$, and $1610 \mathrm{kPa}$ for $\mathrm{B}+10 \mathrm{G}$ at $37^{\circ} \mathrm{C}$, which indicated that Gilsonite modified bitumen achieved the standard requirement of fatigue parameter $\left(G^{*} \sin \delta<5000 \mathrm{kPa}\right)$. On the other hand, by comparing the intermediate temperature $\left(28^{\circ} \mathrm{C}\right)$ of RTFOT+PAV aged bitumens to base bitumen (Fig. 6), there was an improvement in $\delta$ as it goes down from $49.2{ }^{\circ} \mathrm{C}$ to $36.9{ }^{\circ} \mathrm{C}$ which corresponds to $25 \%$ decrement in phase angle after the modification. This is also applicable for other test temperatures. The decrease in $\delta$ value while $\mathrm{G}^{*}$ value being increased by adding Gilsonite, caused the elastic behavior of Gilsonite-modified bitumens to prevail at the new achieved intermediate performance temperatures. 


\subsection{Bending Beam Rheometer (BBR) Test Results}

Creep tests were performed at two different temperatures $\left(-16{ }^{\circ} \mathrm{C}\right.$ and $\left.-22{ }^{\circ} \mathrm{C}\right)$ to determine the performances of the bitumens at low temperatures. In Figures 8 and 9, the creep stiffness of all bitumens satisfied with the Superpave specification at $-16^{\circ} \mathrm{C}$, and all bitumens showed higher m-values than the required minimum at this temperature. The creep stiffness of $\mathrm{B}+10 \mathrm{G}$ was higher than that of $\mathrm{B}$ while its creep rate as $m$-value was lower. Furthermore, the stiffness of samples increased with decreasing temperature while m-value decreased. In addition to this, the creep stiffness and m-values of bitumens were failed to meet the Superpave specification at $-22^{\circ} \mathrm{C}$ which means the low temperature PG grade of all bitumens was determined as PG X-16.

Ten percent addition of natural Gilsonite by weight of bitumen was enough for the beneficial use as it reaches to the highest (high temperature) performance grade of PG 82-16. Hence it is believed that the optimum usage of Gilsonite content is $10 \%$, since the $m$-value of $\mathrm{B}+10 \mathrm{G}$ at $-16{ }^{\circ} \mathrm{C}$ was 0.324 which was very close to 0.300 . On the other hand, the Gilsonite modification did not contribute an enhancement to the low temperature PG grade. For example, $m$-value for $\mathrm{B}+6 \mathrm{G}$ was 0.271 , and for $\mathrm{B}+10 \mathrm{G}$ it was 0.260 . This indicated that with adding Gilsonite, the creep rate decreased, and the bitumen was more brittle and stiffer. At the same time, the PG grade of base and Gilsonite modified bitumen were given in Table 3.

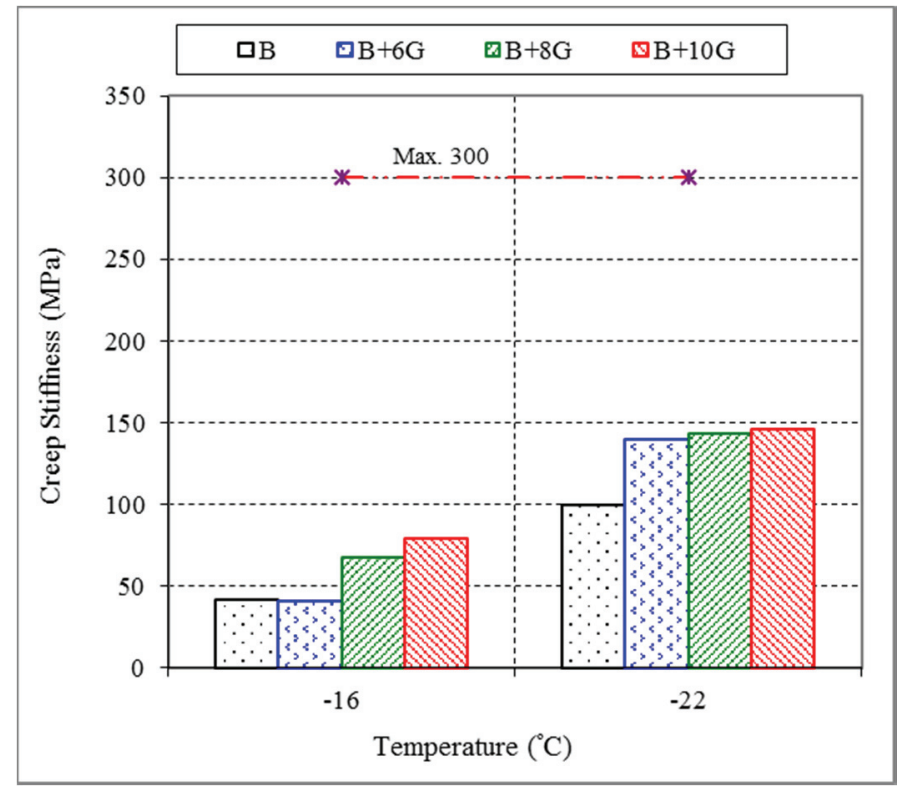

Figure 8 - Creep stiffness of the base and Gilsonite modified bitumens

Block cracking is a low temperature failure in flexible pavement similar to thermal cracking which develops in both longitudinal and transverse directions. Block cracking generally occurs when flexible pavement is old (aged) and traffic volume is low. A parameter named critical temperature $\left(\Delta \mathrm{T}_{\mathrm{c}}\right)$ is relatively up to date for the evaluation of low temperature 
performance of binders against block cracking [39]. $\Delta \mathrm{T}_{\mathrm{c}}$ is obtained by means of the low continuous grade temperature for the stiffness criteria minus low continuous grade temperature for the $\mathrm{m}$-value criteria (which are $10{ }^{\circ} \mathrm{C}$ lower than failure points determined in BBR test) and suggested to examine the ductility loss of aged bitumens leading to block cracking.

$\Delta \mathrm{T}_{\mathrm{c}}$ of the binders was calculated as $-9.9{ }^{\circ} \mathrm{C},-9.5^{\circ} \mathrm{C},-9.7{ }^{\circ} \mathrm{C},-9.9{ }^{\circ} \mathrm{C}$ for the base, $\% 6, \% 8$, and $\% 10$ Gilsonite modified binders, respectively. Lower $\Delta \mathrm{T}_{\mathrm{c}}$ means that binder is vulnerable to cracking at low temperature region. Generally, it is suggested that $\Delta \mathrm{T}_{\mathrm{c}}$ should not be lower than $-5{ }^{\circ} \mathrm{C}$ which means that $\Delta \mathrm{T}_{\mathrm{c}}$ of base and Gilsonite modified binders are not within the acceptable level. However, it should be noted that base and Gilsonite modified binders have very similar $\Delta \mathrm{T}_{\mathrm{c}}$ which signifies that Gilsonite has no positive or negative effect on the loss of ductility of binder.

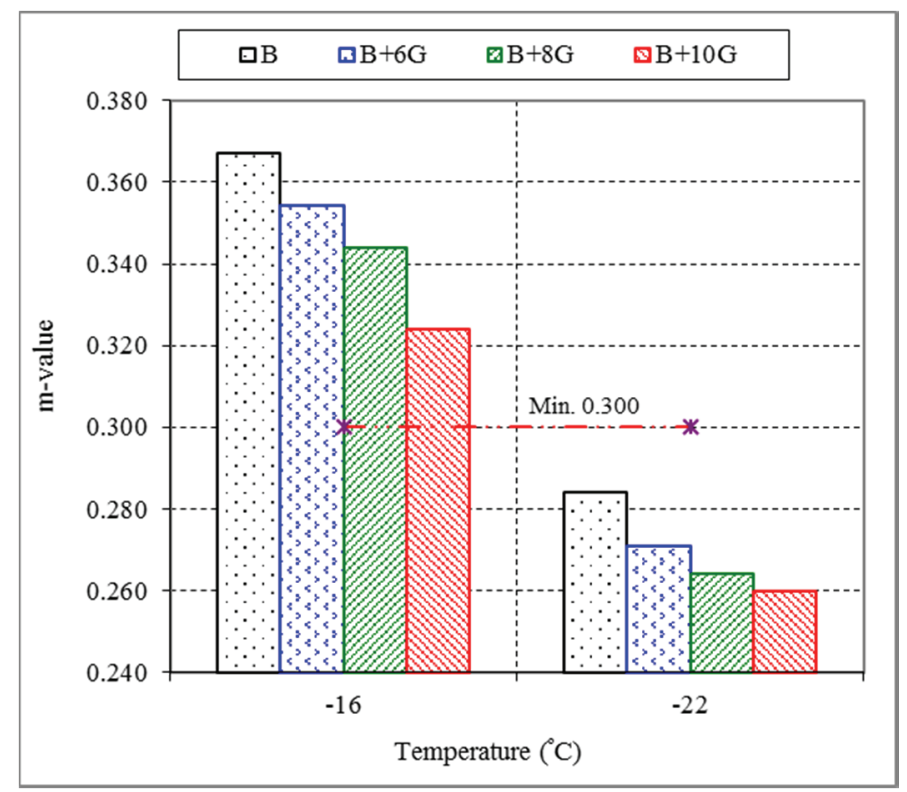

Figure 9 - The m-value of the base and Gilsonite modified bitumens

\subsection{PG Grade and PMBs Requirements}

The enhancement after Gilsonite modification was determined and mentioned in Section 4 as the base (B) is a PG64-16 graded bitumen (in Figs. 2-7) while grade of modified bitumens $(\mathrm{B}+6 \mathrm{G}, \mathrm{B}+8 \mathrm{G}$, and $\mathrm{B}+10 \mathrm{G})$ are $\mathrm{PG} 70-16$, PG 76-16, and PG 82-16, respectively.

Although the modified bitumens did not meet some of the specifications in TS EN 14023 standard, it is believed that the PG grade is a better indicator for bitumen performance, in which rheological parameters are taken into consideration, compared to penetration and softening point tests, in which only basic techniques are applied. Besides, the difference in softening point and penetration after storage stability tests indicated that all modified 
bitumens with respect to their relative PG grades meet the requirements of storage stability in accordance with TS EN 14023 standard. This means that Gilsonite modification achieves the homogeneity and has no phase separation problems.

\section{CONCLUSIONS}

In this study, the effects of natural Gilsonite on the performance properties of bitumen were investigated, and the following conclusions were obtained.

1. The conventional test results showed that the addition of natural Gilsonite remarkably increased the viscosity and stiffness of the base bitumen. The RV results also confirm that Gilsonite had a stiffening effect on the bitumen. In spite of relatively high mixing and compacting temperature ranges of modified bitumens, it was assumed that using Gilsonite could be a suitable modifier taking into consideration the high cost of base bitumen and insufficient resources of this material.

2. The results obtained from elastic recovery showed a slight decrease in elastic recovery after the modification, yet it was considered acceptable.

3. The storage stability test showed that Gilsonite was fully compatible and highly stable with bitumen and had no phase separation in the bitumen during long time of storage process.

4. The natural Gilsonite has a considerable effect on $G^{*}$ and $\delta$ of bitumen. Gilsonite modified bitumen had higher rutting parameter $\left(G^{*} / \sin \delta\right)$ than that of the base bitumen both before and after aging processes. In addition, Gilsonite modification had positive effect on fatigue resistance of bitumen. Moreover, the Gilsonite modification at three different levels of Gilsonite content (i.e, 6, 8, and 10\%) provided high performance grade of bitumens of PG 70-Y, PG 76-Y, and PG 82-Y, respectively.

5. BBR test results showed that Gilsonite additive had no positive effect on lowtemperature cracking resistance of bitumen and caused the creep rate decrease. The low performance grade at three levels of Gilsonite modification of 6,8 , and $10 \%$ were found as PG X-16, PG X-16, and PG X-16, respectively. This was attributed to the stiffening effect of Gilsonite additive which is also compatible with elastic recovery results.

According to the findings, Gilsonite has positive effects on the physical properties of bitumen such as stiffening meaning that the pavements become more resistant to permanent deformation after the modification. Although the Gilsonite contributes no enhancement against low-temperature cracking, it provides a positive effect on high temperatures. The use of $10 \%$ of Gilsonite improves the performance grade of base bitumen from PG 64-16 up to PG 82-16 which corresponds to an enhancement of three levels. For this reason, it is advised to use Gilsonite at high temperature regions and/or very heavy loaded flexible pavement projects up to $10 \%$. It should also be noted that light modification of Gilsonite is recommended in cold regions since the modifier increases the stiffness of bitumen. 


\section{Symbols}

$\begin{array}{ll}\text { DSR } & \text { : Dynamic shear rheometer } \\ \boldsymbol{G}^{*} & \text { : Complex shear modulus } \\ \boldsymbol{m} \text {-value } & : \text { Creep rate } \\ \boldsymbol{P A V} & : \text { Pressure aging vessel } \\ \boldsymbol{P G} & : \text { Performance grade } \\ \boldsymbol{P M B} & : \text { Polymer modified bitumen } \\ \boldsymbol{R T F O T} & : \text { Thin film oven test } \\ \boldsymbol{R V} & : \text { Rotational viscometer } \\ \boldsymbol{S} & : \text { Creep stiffness } \\ \boldsymbol{\delta} & : \text { Phase angle } \\ \boldsymbol{\eta}_{\text {base }} & : \text { Viscosity of base bitumen } \\ \boldsymbol{\eta}_{\text {modified }} & : \text { Viscosity of modified bitumen }\end{array}$

\section{References}

[1] Garcia, A., Schlangen, E., Ven, M., Sierra-Beltrana, G., Preparation of capsules containing rejuvenators for their use in asphalt concrete, Journal of Hazardous Materials, 11, 184-603, 2010.

[2] Lu, X.H., Isacsson, U., Chemical and rheological evaluation of ageing properties of SBS polymer modified bitumens, Fuel, 77:9, 961-972, 1998.

[3] Qadir, A., Rutting performance of polypropylene modified asphalt concrete, International Journal of Civil Engineering, 12:3, 304-312, 2014.

[4] Lu, X.H., Isacsson, U., Compatibility and storage stability of styrene-butadiene-styrene copolmer modified bitumens, Materials and Structures, 30:10, 618-626, 1997.

[5] Ma, T., Wang, H., Zhao, Y., Huang, X., Wang, S., Laboratory investigation of crumb rubber modified asphalt binder and mixtures with warm-mix additives, International Journal of Civil Engineering, doi:10.1007/s40999-016-0040-3, 2016.

[6] Sureshkumar, M.S., Filippi, S., Polacco, G., Kazatchkov, I., Stastna, J., Zanzotto, L., Internal structure and linear viscoelastic properties of EVA/asphalt nanocomposites, European Polymer Journal, 46, 621-633, 2010.

[7] Gad, Y.H., Magida, M.M., El-Nahas, H.H., Effect of ionizing irradiation on the thermal blend of waste low density polyethylene/ethylene vinyl acetate/bitumen for some industrial applications, Journal of Industrial and Engineering Chemistry, 16:6, 10191024, 2010.

[8] Ahmedzade, P., Fainleib, A., Gunay, T., Grygoryeva, O., Modification of bitumen by electron beam irradiated recycled low density polyethylene, Construction and Building Materials, 69, 1-9, 2014. 
[9] Fu, H., Xie, L., Dou, D., Li, L., Yu, M., Yao, S., Storage stability and compatibility of asphalt binder modified SBS graft copolymer, Construction and Building Materials, 21, 1528-1533, 2007.

[10] Yilmaz, M., Yamaç, Ö.E., Evaluation of Gilsonite and styrene-butadiene-styrene composite usage in bitumen modification on the mechanical properties of hot mix asphalts, J. Mater. Civ. Eng., 29:9, 04017089, 2017.

[11] Kök, B.V., Yilmaz, M., Guler, M., Evaluation of high temperature performance of SBS + Gilsonite modified binder, Fuel, 90, 3093-3099, 2011.

[12] Bahia, H.U., Hanson, D.I., Zeng, M., Zhai, H., Khatri, M.A., Anderson, R.M., Characterization of modified asphalt binders in Superpave mix design (Project No. 910 FY'96), NCHRP, Washington, 2001.

[13] Nasrekani, A.A., Naderi, K., Nakhaei, M., Mahmoodinia, N., High-temperature performance of Gilsonite modified asphalt binder and asphalt concrete, Petroleum Science and Technology, 34:21, 1783-1789, 2016.

[14] Babagoli, R., Hasaninia, M., Namazi, N.M., Laboratory evaluation of the effect of Gilsonite on the performance of stone matrix asphalt mixtures, Road Materials and Pavement Design, 16:4, 889-906, 2015.

[15] Jahanian, H.R., Shafabakhsh, G., Divandari, H., Performance evaluation of Hot Mix Asphalt (HMA) containing bitumen modified with Gilsonite, Construction and Building Materials, 131, 156-164, 2017.

[16] Brown, S.F., Rowlett, R.D., Boucher, J.L., Asphalt modification, Proceedings of the conference, The United States strategic highway research program, London: Institute of Civil Engineers, London, 181-203, 1990.

[17] Ameri, M., Mansourian, A., Ashani, S.S., Yadollahi, G., Technical study on the Iranian Gilsonite as an additive for modification of asphalt binders used in pavement construction, Constr. Build. Mater., 25:3, 1379-1387, 2011.

[18] Nasrekani, A.A., Nakhaei, M., Naderi, K., Fini, E., Aflaki, S., Improving moisture sensitivity of asphalt concrete using natural bitumen (Gilsonite), Transportation Research Board 96th Annual Meeting, Washington DC, United States, http://amonline.trb.org/, 2017.

[19] Anderson, D.A., Maurer, D., Ramirez, T., Christensen, D.W., Marasteanu, M.O., Mehta, Y., Field performance of modified asphalt binders evaluated with superpave test methods: 1-80 test project, Transportation Research Record 1661, 60-68, 1999.

[20] Aflaki, S., Tabatabaee, N., Proposals for modification of Iranian bitumen to meet the climatic requirements of Iran, Construction and Building Materials, 23, 2141-2150, 2009.

[21] Tang, N., Huang, W., Zheng, M., Hu, J., Investigation of Gilsonite-, polyphosphoric acid- and styrene-butadiene-styrene-modified asphalt binder using the multiple stress creep and recovery test, Road Materials and Pavement Design, 18:5, 1084-1097, 2017.

[22] Widyatmoko, I., Elliott, R., Characteristics of elastomeric and plastomeric binders in contact with natural asphalts, Constr. Build. Mater., 22, 239-249, 2008. 
[23] Quintana, H.A.R., Noguera, J.A.H., Bonells, C.F.U., Behavior of Gilsonite-modified hot mix asphalt by wet and dry processes, J. Mater. Civ. Eng., 28:2, 04015114, 2016.

[24] Zhi, S., Gun, W.W., Hui, L.X., Bo, T., Evaluation of fatigue crack behavior in asphalt concrete pavements with different polymer modifiers, Construction and Building Materials, 27, 117-125, 2012.

[25] Huang, B., Li, G., Shu, X., Investigation into three-layered HMA mixtures, Composites, 37, 679-690, 2006.

[26] Słowik, M., Bilski, M., An experimental study of the impact of aging on Gilsonite and trinidad epuré modified asphalt binders properties, Baltic Journal of Road \& Bridge Engineering, 12:2, 71-81, 2017.

[27] TS EN 14023, Bitumen and bituminous binders - Framework specification for polymer modified bitumens, Turkish and European standard, 2006.

[28] EN 13399, Bitumen and Bituminous Binders - Determination of Storage Stability of Modified Bitumen, European standard, 2010.

[29] Anderson, D., Christensen, D.W., Bahia, H.U., Dongre, R., Sharma, M.G., Antle, C.E., Button, J., Strategic highway research program binder characterization: Physical properties. SHRP-A-369, Vol. 3, National Research Council, Washington, DC, 1994.

[30] Bahia, H.U., Anderson, D.A., Strategic highway research program binder rheological parameters: background and comparison with conventional properties, Transportation Research Record, TRB, National Research Council, 32-39, Washington, DC, 1995.

[31] AASHTO: AASHTO T 316- Viscosity determination of asphalt binder using rotational viscometer, Washington D.C., 2004.

[32] The Asphalt Institute, Superpave mix design: Superpave series no. 2, (SP-2), 2001.

[33] EN 12607-1, Bitumen and bituminous binders: Determination of the resistance to hardening under the influence of heat and air - Part 1: RTFOT method, European standard, 2003.

[34] AASHTO: AASHTO T 240- Effect of heat and air on a moving film of asphalt (Rolling Thin-Film Oven Test) standard test methods, Washington D.C., 2013.

[35] AASHTO: AASHTO R 28- Accelerated aging of asphalt binder using a pressurized aging vessel (PAV) standard test methods, Washington D.C., 2012.

[36] AASHTO: AASHTO T 315- Determining the rheological properties of asphalt binder using a dynamic shear rheometer (DSR) standard test methods, Washington D.C., 2012.

[37] AASHTO: AASHTO T 313- Determining the flexural creep stiffness of asphalt binder using the bending beam rheometer (BBR) standard test methods, Washington D.C., 2012.

[38] ASTM: ASTM D6373- Standard specification for performance graded asphalt binder, West Conshohocken, PA, 1999.

[39] Anderson, R. M., King, G. N., Hanson, D. I., Blankenship, P. B., Evaluation of the relationship between asphalt binder properties and non-load related cracking. Journal of the Association of Asphalt Paving Technologists, 80, 2011. 